LETTER

\section{Population-based Neisseria gonorrhoeae, Chlamydia trachomatis and Trichomonas vaginalis prevalence using discarded, deidentified urine specimens previously collected for drug testing}

We used a novel method to test for STIs among a non-healthcare-seeking military population in the San Diego region of California. Active-duty US Navy and Marine Corps personnel were randomly selected to provide urine specimens to Navy Drug Screening Laboratory, San Diego in October and November 2013 for the Department of Defense drug testing programme. If specimens screened negative for drugs (>99\% of samples), urine specimens were discarded, deidentified and subsequently tested for Chlamydia trachomatis (CT), Neisseria gonorrhoeae (GC) and Trichomonas vaginalis (TV) using the Aptima Combo 2 and TV assay as specified by the manufacturer (Hologic, San Diego, CA, USA). The Tigris direct tube sampling system was used for highthroughput nucleic acid amplification testing (NAAT). Urine specimens older than 6 days were not tested due to sample degradation concerns.

The overall prevalence of CT was $2.1 \%$ (95\% CI 1.79 to $2.36, \mathrm{n}=205 / 9953)$, GC $0.01 \%$ (95\% CI 0.00 to $0.07, \mathrm{n}=1 / 9953$ ) and TV $0.12 \%$ (95\% CI 0.03 to 0.38 , $\mathrm{n}=3 / 2553$ ).

Prevalence was not significantly different from civilian estimates. ${ }^{1}$ Prior military data show higher prevalence ${ }^{2}$ but include higher prevalence groups (recruits, larger proportion of female or African American race/ethnicity) not comparable to the regional military population. In the USA, TV prevalence is higher in women than men $(3.2 \%$ vs $1.9 \%$, see online supplementary material), African Americans than Whites $(6.9 \%$ vs $1.2 \%)$ and those $\geq 25$ than $18-20$ year olds ( $4 \%$ vs $1.5 \%$ ) which may partially account for the low TV prevalence $(0.12 \%)$; the military population is predominantly male $(86 \%)$, white $(69 \%)$ and young $(51 \% \leq 25$ years old $)$.

This testing method was effective for obtaining a standardised STI prevalence in a non-healthcare-seeking US military population using specimens previously collected for drug testing. This method could be adjusted for monitoring changes in STI prevalence, or for measuring asymptomatic infections within the activeduty military population.

\section{Judith Harbertson, ${ }^{1,2,3}$ Matthew Jamerson, ${ }^{4}$ Paul C F Graf, ${ }^{5,6}$ Lisa Kennemur, ${ }^{4}$ Brent House, ${ }^{5}$ Nelson L Michael, ${ }^{1}$ Paul Scott, ${ }^{1}$ Brad Hale $^{3,7}$}

1 US Military HIV Research Program, Walter Reed Army Institute of Research, San Diego, California, USA ${ }^{2}$ Health Sciences Business Unit, Leidos, Inc, San Diego, California, USA

${ }^{3}$ Department of Defense HIV/AIDS Prevention Program (DHAPP), Naval Health Research Center, San Diego, California, USA

${ }^{4}$ Navy Drug Screening Laboratory, US Navy, San Diego, California, USA

${ }^{5}$ Naval Medical Center, San Diego, California, USA ${ }^{6}$ Operational Infectious Diseases Department, Naval Health Research Center, San Diego, California, USA ${ }^{7}$ University of California, San Diego, California, USA

Correspondence to Dr Judith Harbertson, US Military HIV Research Program, Naval Health Research Center, San Diego 92152, California, USA; judith.harbertson. ctr@mail.mil

\section{Handling editor Khalil G Ghanem}

Acknowledgements The authors would like to thank Danilo Fernandez, Don Mercado, Alex Natividad and Cristeta Olimpo for performing the Aptima Combo 2 and Aptima Trichomonas vaginalis testing, Melinda Balansay-Ames, Chris Myers and Gary Brice for PCRbased sex determination testing, and Kimberly De Vera for assisting with references and manuscript writing/ compilation.

Contributors $\mathrm{JH}, \mathrm{BH}$ and PS collaborated on study design, acquisition of data and analysis and interpretation of data; drafted the manuscript and provided critical revision of the manuscript. MJ and LK collaborated on study design, acquisition of data and critical review of the manuscript. NM collaborated on study design and critical review of the manuscript. PCFG and $\mathrm{BH}$ collaborated on study design, specimen collection and testing and critical review of the manuscript.

Funding This work was supported by a cooperative agreement (W81XWH-07-2-0067) between the Henry M. Jackson Foundation for the Advancement of Military Medicine, Inc., and the US Department of Defense under work unit no. 60546

Disclaimer I am a military service member (or employee of the US Government). This work was prepared as part of my official duties. Title 17, U.S.C. $\S 105$ provides the 'Copyright protection under this title is not available for any work of the United States Government.' Title 17, USC, $\$ 101$ defines a US Government work as work prepared by a military service member or employee of the US Government as part of that person's official duties. Report No. 17-43 supported by a cooperative agreement (W81XWH-07-2-0067) between the Henry M. Jackson Foundation for the Advancement of Military Medicine, Inc., and the US Department of Defense, under Work Unit No. 60546. The views expressed in this article are those of the authors and do not necessarily reflect the official policy or position of the Department of the Navy, Department of the Army, Department of the Air Force, Department of Veterans Affairs, Department of Defense, or the U.S. Government. Approved for public release; distribution unlimited. This research has been conducted in compliance with all applicable federal regulations governing the protection of human subjects in research (Protocol NHRC.2013.0012).

Competing interests None declared.

Provenance and peer review Not commissioned; internally peer reviewed.

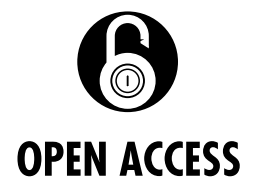

Open Access This is an Open Access article distributed in accordance with the terms of the Creative Commons Attribution (CC BY 4.0) license, which permits others to distribute, remix, adapt and build upon this work, for commercial use, provided the original work is properly cited. See: http://creativecommons.org/licenses/by/4.0/

(c) Article author(s) (or their employer(s) unless otherwise stated in the text of the article) 2018. All rights reserved. No commercial use is permitted unless otherwise expressly granted.

- Additional material is published online only. To view please visit the journal online (http://dx.doi.org/ 10.1136/sextrans-2017-053355)

\section{D) Check for updates}

To cite Harbertson J, Jamerson M, Graf PCF, et al. Sex Transm Infect 2018;94:123.

Received 28 July 2017

Revised 18 September 2017

Accepted 23 September 2017

Published Online First 24 October 2017

Sex Transm Infect 2018;94:123.

doi:10.1136/sextrans-2017-053355

\section{REFERENCES}

1 Torrone E, Papp J, Weinstock H. Centers for Disease Control and Prevention (CDC). Prevalence of Chlamydia trachomatis genital infection among persons aged 14-39 years-United States, 2007-2012. MMWR Morb Mortal Wkly Rep 2014;63:834-7.

2 Rietmeijer CA, Hopkins E, Geisler WM, et al. Chlamydia trachomatis positivity rates among men tested in selected venues in the United States: a review of the recent literature. Sex Transm Dis 2008;35(11 Suppl):S8-S18. 